\title{
From Bench to Bedside in Neuropsychology
}

\author{
Professor Glyn W. Humphreys' Legacy
}

\author{
NELE DEMEYERE
}

It has now been slightly more than a year since we suddenly and tragically lost one of the great neuropsychologists of our time. Professor Glyn Humphreys passed away unexpectedly on January 14, 2016, while in Hong Kong as a distinguished visiting professor. A year has passed, but those who worked close to him and whose lives were touched by his understated leadership, sharp mind, clear insights, and humanity will always miss his gentle guidance. He leaves a tremendous legacy, in many research domains within psychology and neuroscience, including neuropsychology, cognitive psychology, computational modeling, social neuroscience, neurorehabilitation, and cognitive screening and diagnostics. His enormous influence and standing in the field were recognized internationally by many awards and accolades, such as The Spearman Medal (1986), the British Psychological Society's Cognitive Psychology section prize (1999 and 2012) and President's Award (1999), a Humboldt Research Fellowship (1998), the Royal Society Wolfson merit award (2007), the Donald Broadbrent Prize from the European Society for Cognitive Psychology (2013), and the Leibniz Professorship and Special Professorship of the Chinese Academy of Sciences, as well as the British Psychological Society Life Time Achievement Award (2015). He was elected a member of the Royal Society for Medicine (2008) and a fellow of the British Academy (2009).
These esteemed awards complement the daily leadership tasks he took on, as editor of the Quarterly Journal of Experimental Psychology, Visual Cognition (as founding Editor), and the Journal of Experimental Psychology: Human Perception and Performance. He was head of the School of Psychology at the University of Birmingham for 15 years, and head of the Department of Experimental Psychology at the University of Oxford from 2011, where he established the Cognitive Neuropsychology Centre.

Listing these markers of esteem, however, cannot do justice to the kind of person Glyn Humphreys was. He was much more than a star academic; he really cared deeply about his colleagues, his students, and the many patients who contributed to the research. Throughout his career he and Professor Jane Riddoch set about improving neuropsychological assessments and neurorehabilitation for patients after brain injury. It is this legacy in neuropsychological applications and the journey from laboratory-based experiments to applied and widely used cognitive screening and assessments that this tribute will focus on.

Professor Humphreys' early investigations in visual cognition and visual agnosia directly led to the development of the Birmingham Object Recognition Battery $\left.[B O R B]^{1}\right)$. It started with a theoretical interest in Marr's posthumously published work on the derivation of canonical axes from an image. ${ }^{2}$ In particular, 
the importance of the axes of elongation for object recognition, also highlighted by Biederman's work in his "recognition by components" theory ${ }^{3}$ struck a chord. When reviewing some of the classic work on impairments to visual object recognition following right hemisphere lesions, particularly on an unusual views object naming task, ${ }^{4}$ he was driven to investigate the components underlying these unusual views. He did so by differentiating between views that foreshorten the main axis and views that maintained the main elongation axis, but minimized the saliency of identifying features.

In their seminal paper, Humphreys and Riddoch ${ }^{5}$ found a double dissociation, with four patients with acquired brain damage, demonstrating a specific impairment in matching objects from foreshortened views to a target canonical view, with no problems identifying the minimal feature view, and a single patient who showed impaired matching only when the saliency of the target's distinctive features was reduced. This one patient with visual agnosia was of particular interest and became the subject of many articles to follow with the famous initials H.J.A., most notably described in the book To See But Not To See: A Case Study of Visual Agnosia. ${ }^{6}$ H.J.A. demonstrated intact low level vision and binding features into edges, intact shape discriminations, and intact copying, but severely impaired figureground segmentation. This provided evidence for a further fractionation of Lissauer's ${ }^{7}$ two stage framework for understanding disorders of object processing: apperception and association, because, within apperceptive agnosia, H.J.A.'s impairment in object recognition was specific to an inability to integrate form information. Unlike patients with form agnosia, such as the patients reported by Efron ${ }^{8}$ and Benson and Greenberg, ${ }^{9}$ H.J.A. was able to copy and to discriminate between shapes.
Humphreys and Riddoch coined the concept and term "integrative agnosia." 10 The tests used in these initial patient studies were structured under four headers: Low Level Vision, Mid Level Vision, Semantics, and Object Recognition, and were published in the first standardized neuropsychological clinical test from the Humphreys' laboratory: the BORB. ${ }^{11}$

Over the years, broader interests came with the arrival of many different patients. Professor Humphreys and his group published countless articles on a variety of neuropsychological syndromes and symptoms, furthering our theoretical understanding of cognition, contributing to knowledge about underlying neuroanatomical and functional processes, and demonstrating effective methods of intervention. For the purpose of this tribute, it is impossible to be exhaustive, but some examples include studies on neglect, ${ }^{12,13,14}$ extinction, ${ }^{15,16,17}$ aphasia, ${ }^{18,19}$ alexia, ${ }^{20,21}$ letter by letter reading, ${ }^{22}$ prosopagnosia, ${ }^{23}$ numerical cognition, ${ }^{24,25}$ apraxia, ${ }^{26,27,28}$ short-term memory, ${ }^{29,30}$ simultanagnosia, $31,32,33$ and even deficits in theory of mind. $34,35,36$

With this varied experience and expertise also came an awareness of a gap in cognitive neuropsychological assessments: the need for an initial cognitive screen for patients with acquired brain injuries (e.g., stroke), that would be both "broad and shallow." Many neuropsychological domain-specific batteries existed, but to use all of them for every new patient would take hours to complete. To complete only one specific domain test would ignore the many often co-occurring cognitive difficulties in attention, memory, and numerical cognition. There was a need for a neuropsychological screening approach that would cover a range of cognitive domains, and that could be delivered efficiently. In addition, it was to be 
designed to maximize inclusion by being aphasia and neglect friendly. This led to the development of the Birmingham Cognitive Screen (BCoS). ${ }^{37}$ The test philosophy was made explicit: to use short high-frequency words throughout, use vertical layouts and multimodal presentations, and to maximize time efficiency by designing tests that would incorporate several measures. The tests were made to be sensitive (so that they would detect a problem if one were present) and indicative of domain deficits, although not detailed. For example, the language tests would pick up a problem in object naming, but would not investigate the nature of the exact naming problem. For the first time, neuropsychological expertise in the form of a user-friendly first line cognitive screen was within the reach of interested allied health professionals, who were not necessarily neuropsychologists. BCoS can be delivered within 1 hour, at subacute stages of stroke, and gives a relatively detailed breakdown of cognitive function in five domains: Attention and Executive Function, Language, Memory, Numerical Ability, and Praxis. A recent article summarized the ability of BCoS to identify differential cognitive profiles, informing rehabilitation and contributing to the prediction of longer-term outcomes. ${ }^{38}$

Although BCoS filled a gap in cognitive profiling, where there was time to do so (where patients and staff could support an hour of assessment), the timepressured environments of acute stroke units required a shorter screen. At the time, no stroke-specific cognitive screen existed, and short dementia screens, such as the Mini Mental State Examination ${ }^{39}$ or Montreal Cognitive Assessment ${ }^{40}$ were routinely used. However, these were developed to screen for dementia, and not necessarily suited to screen for common post- stroke cognitive impairments: the cognitive profile of a stroke survivor with a focal infarct or bleed is very different from a neurodegenerative global impairment profile. In particular, the language demands for these screens are high, and the presence of neglect may contaminate task performance. ${ }^{41}$ The Oxford Cognitive Screen (OCS ${ }^{42}$ provided a tailored stroke-specific solution, one that was not relying on spoken responses, and not impacted by neglect. The OCS focussed on briefly screening for impairments in the same five cognitive domains as set out in the BCoS, delivering a cognitive profile to inform the multidisciplinary team about specific cognitive impairments, rather than an overall pass/fail judgement. This shorter screen, which can be completed in under 20 minutes, has gained great traction in clinical practice, and has at the point of writing already been adopted in over 250 National Health Service (NHS) units in the United Kingdom and several translations have been completed ${ }^{43,44}$ or are underway (www.ocs-test.org).

The latest developments in Professor Humphreys' efforts in improving neuropsychological screening were through the development of further tablet-based assessments of the domain-specific OCS as well as OCS-Plus: aimed to briefly and sensitively assess broader domaingeneral functions, using the mobile technology to automatically derive not only outcome, but also measurements of process and strategies. This work is being continued by our group at the Cognitive Neuropsychology Centre, and a first study using this latest approach to demonstrate effects of ageing and cognitive reserve in a large low-literacy cohort in South Africa was published in his name posthumously. ${ }^{45}$

Professor Glyn Humphreys' legacy is immense, and although his specific impact on improving real-life clinical practice is but one strand of his lasting influence, this tribute specifically set out to celebrate this aspect of his career, which served as a bridge joining bench 
and bedside. His portfolio of assessments and screening, built on neuropsychological theory expertise and translated to clinical practice improvements will, no doubt, continue to inspire future generations of researchers to walk in the footsteps of this giant in neuropsychology.

\section{Notes}

1. Riddoch MJ, Humphreys GW. Birmingham Object Recognition Battery. Lawrence Erlbaum Associates; 1993.

2. Marr D. Vision: A Computational Investigation into the Human Representation and Processing of Visual Information. New York: Henry Holt and Co. 1982;2:4-2.

3. Biederman I. Recognition-by-components: A theory of human image understanding. Psychological Review 1987;94(2):115.

4. Warrington EK, Taylor AM. The contribution of the right parietal lobe to object recognition. Cortex 1973;9(2):152-64.

5. Humphreys GW, Riddoch MJ. Routes to object constancy: Implications from neurological impairments of object constancy. The Quarterly Journal of Experimental Psychology. A, Human Experimental Psychology 1984;1;36(3):385-415.

6. Humphreys GW, Riddoch MJ. To See But Not To See: A Case Study of Visual Agnosia, Psychology Press, 1987; available at https: / / books.google.com / books?hl=en\&lr $=\& i d=0 \mathrm{E}$ $\mathrm{fKzK} 2 \mathrm{jAJ0C} \& \mathrm{oi}=\mathrm{fnd} \& \mathrm{pg}=\mathrm{PA} 1 \& \mathrm{dq}=\mathrm{Humphr}$ eys\&ots $=Q W Z b M I x M 32 \& s i g=I F E n D m J M 5 b$ N7wWKxRrW523irO34 (last accessed 13 Mar 2017).

7. Lissauer H. Ein Fall von Seelenblindheit nebst einem Beitrage zur Theorie derselb. [A case of visual agnosia with a contribution to theory] European Archives of Psychiatry and Clinical Neuroscience 1890;21(2):222-70.

8. Efron R. What is perception? In: Proceedings of the Boston Colloquium for the Philosophy of Science, Springer, 1969; available at http: / / link.springer.com/chapter/10.1007/978-94-0103378-7_4 (last accessed 13 Mar 2017).

9. Benson DF, Greenberg JP. Visual form agnosia: A specific defect in visual discrimination. Archives of Neurology 1969;20(1):82-9.

10. Riddoch MJ, Humphreys GW. A case of integrative visual agnosia. Brain 1987;110(6):1431-62.

11. See note 1, Riddoch, Humphreys 1993.

12. Riddoch MJ, Humphreys GW. The effect of cueing on unilateral neglect. Neuropsychologia 1983;21(6):589-99.

13. Edwards MG, Humphreys GW. Pointing and grasping in unilateral visual neglect: effectof on-line visual feedback in grasping. Neuropsychologia 1999;37(8):959-73.

14. Bickerton LW, Samson D, Williamson J, Humphreys WG. Separating forms of neglect using the Apples Test: validation and functional prediction in chronic and acute stroke. Neuropsychology 2011;25:567-80.

15. Gilchrist ID, Humphreys GW, Riddoch MJ. Grouping and extinction: Evidence for lowlevel modulation of visual selection. Cognitive Neuropsychology 1996;13(8):1223-49.

16. Punt DT, Riddoch JM, Humphreys WG. Motor extinction: A deficit of attention or intention? Frontiers in Human Neuroscience 2013;7:644.

17. Soto D, Humphreys GW. Seeing the content of the mind: Enhanced awareness through working memory in patients with visual extinction. Proceedings of the National Academy of Sciences of the United States of America 2006;103(12): 4789-92.

18. Forde E, Humphreys GW. Refractory semantics in global aphasia: On semantic organisation and the access-storage distinction in neuropsychology. Memory 1995;3(3-4):265-307.

19. Francis D, Clark N, Humphreys G. The treatment of an auditory working memory deficit and the implications for sentence comprehension abilities in mild "receptive" aphasia. Aphasiology 2003;17(8):723-50.

20. Price CJ, Humphreys GW. Contrasting effects of letter-spacing in alexia: Further evidence that different strategies generate word length effects in reading. Quarterly Journal of Experimental Psychology 1995;48(3):573-97.

21. Osswald K, Humphreys GW, Olson A. Words are more than the sum of their parts: Evidence for detrimental effects of word-level information in alexia. Cognitive Neuropsychology 2002; 19(8):675-95.

22. Price CJ, Humphreys GW. Letter-by-letter reading? Functional deficits and compensatory strategies. Cognitive Neuropsychology 1992;9(5): 427-57.

23. Riddoch MJ, Johnston RA, Bracewell RM, Boutsen L, Humphreys GW. Are faces special? A case of pure prosopagnosia. Cognitive Neuropsychology 2008;25(1):3-26.

24. Watson DG, Humphreys GW. The magic number four and temporo-parietal damage: Neurological impairments in counting targets amongst distractors. Cognitive Neuropsychology 1999;16(7):609-29.

25. Demeyere N, Rotshtein P, Humphreys GW. The neuroanatomy of visual enumeration: differentiating necessary neural correlates for subitizing versus counting in a neuropsychological voxel-based morphometry study. Journal of Cognitive Neuroscience 2012;24(4):948-64. 
26. Riddoch MJ, Humphreys GW, Price CJ. Routes to action: Evidence from apraxia. Cognitive Neuropsychology 1989;6(5):437-54.

27. Pilgrim E, Humphreys GW. Impairment of action to visual objects in a case of ideomotor apraxia. Cognitive Neuropsychology 1991;8(6): 459-73.

28. Bickerton W-L, Riddoch MJ, Samson D, Balani AB, Mistry B, Humphreys GW. Systematic assessment of apraxia and functional predictions from the Birmingham Cognitive Screen. Journal of Neurology, Neurosurgery. and Psychiatry 2012 May 1;83(5): 513-21.

29. Forde EM, Humphreys GW. The role of semantic knowledge in short-term memory. Neurocase 2002;8(1):13-27.

30. Gillebert CR, Humphreys GW. Neuropsychological evidence for a spatial bias in visual short-term memory after left posterior ventral damage. Cognitive Neuropsychology 2008; 25(3):319-42.

31. Riddoch MJ, Humphreys GW. Object identification in simultanagnosia: When wholes are not the sum of their parts. Cognitive Neuropsychology 2004;21(2-4):423-41.

32. Humphreys GW, Price CJ. Visual feature discrimination in simultanagnosia: A study of two cases. Cognitive Neuropsychology 1994; 11(4):393-434.

33. Demeyere N, Rzeskiewicz A, Humphreys KA, Humphreys GW. Automatic statistical processing of visual properties in simultanagnosia. Neuropsychologia 2008;46(11):2861-4.

34. Apperly IA, Samson D, Chiavarino C, Humphreys GW. Frontal and temporoparietal lobe contributions to theory of mind: Neuropsychological evidence from a falsebelief task with reduced language and executive demands. Journal of Cognitive Neuroscience 2004;16(10):1773-84.

35. Apperly IA, Samson D, Humphreys GW. Domain-specificity and theory of mind: evaluating neuropsychological evidence. Trends in Cognitive Sciences 2005;9(12):572-7.

36. Samson D, Houthuys S, Humphreys GW. Self-perspective inhibition deficits cannot be explained by general executive control difficulties. Cortex 2015;70:189-201.
37. Humphreys GW, Bickerton WL, Samson D, Riddoch MJ. BCoS Cognitive Screen. Hove, UK: Psychology Press; 2012

38. Bickerton W-L, Demeyere N, Francis D, Kumar V, Remoundou M, Balani A, et al. The BCoS cognitive profile screen: Utility and predictive value for stroke. Neuropsychology 2015;29:638-48.

39. Folstein MF, Folstein SE, McHugh PR. "Minimental state". A practical method for grading the cognitive state of patients for the clinician. Journal of Psychiatric Research 1975;12(3): 189-98.

40. Nasreddine SZ, Phillips AN, Bedirian V, Charbonneau S, Whitehead V, Collin I, et al. The montreal cognitive assessment, MoCA: A brief screening tool for mild cognitive impairment. Journal of the American Geriatric Society 2005;53:695-9.

41. Demeyere N, Riddoch MJ, Slavkova ED, Jones K, Reckless I, Mathieson P, et al. Domain-specific versus generalized cognitive screening in acute stroke. Journal of Neurology 2016;263:306-15.

42. Demeyere N, Riddoch MJ, Slavkova ED, Bickerton W-L, Humphreys GW. The Oxford Cognitive Screen (OCS): Validation of a strokespecific short cognitive screening tool. Psychological Assessment 2015;27(3):883-94.

43. Kong AP-H, Lam PH-P, Ho DW-L, Lau JK, Humphreys GW, Riddoch J, et al. The Hong Kong version of the Oxford Cognitive Screen (HK-OCS): Validation study for Cantonesespeaking chronic stroke survivors. Aging, Neuropsychology, and Cognition 2016;23: 530-48.

44. Mancuso M, Varalta V, Sardella L, Capitani D, Zoccolotti P, Antonucci G, et al. Italian normative data for a stroke specific cognitive screening tool: The Oxford Cognitive Screen (OCS). Neurological Sciences 2016;37:1713-21.

45. Humphreys GW, Duta M, Montana L, Demeyere N, McCrory C, Rohr J, et al. Cognitive function in low-income and low- literacy settings: Validation of the tablet-based Oxford Cognitive Screen in the health and aging in Africa: A Longitudinal Study of an INDEPTH Community in South Africa (HAALSI). J Gerontol Psychol Sci. 2017;72:38-50. 